\title{
Test-Retest of Long Latency Auditory Evoked Potentials (P300) with Pure Tone and Speech Stimuli
}

\author{
Ana Paula Perez ${ }^{1,2}$ Karin Ziliotto ${ }^{1} \quad$ Liliane Desgualdo Pereira $^{1}$ \\ ${ }^{1}$ Department of Phonoaudiology, Escola Paulista de Medicina - \\ UNIFESP, São Paulo, SP, Brazil \\ 2 Department of Phonoaudiology Specialization, Universidade Federal \\ Fluminense, Nova Friburgo, Rio de Janeiro, RJ, Brazil \\ Address for correspondence Ana Paula Perez, PhD, Universidade \\ Federal Fluminense - FEF (Formação específica em Fonoaudiologia), \\ Rua Dr. Silvio Henrique Braunie 22 Nova Friburgo Rio de Janeiro \\ 28625650, Brazil (e-mail: popiperez@ig.com.br).
}

Int Arch Otorhinolaryngol 2017;21:134-139.

\begin{abstract}
Introduction Long latency auditory evoked potentials, especially P300, have been used for clinical evaluation of mental processing. Many factors can interfere with Auditory Evoked Potential - P300 results, suggesting large intra and inter-subject variations.

Objective The objective of the study was to identify the reliability of P3 components (latency and amplitude) over 4-6 weeks and the most stable auditory stimulus with the best test-retest agreement.

Methods Ten normal-hearing women participated in the study. Only subjects without auditory processing problems were included. To determine the P3 components, we elicited long latency auditory evoked potential (P300) by pure tone and speech stimuli, and retested after 4-6 weeks using the same parameters. We identified P300 latency and amplitude by waveform subtraction.

Results We found lower coefficient of variation values in latency than in amplitude, with less variability analysis when speech stimulus was used. There was no significant correlation in latency measures between pure tone and speech stimuli, and sessions. There was a significant intrasubject correlation between measures of latency and amplitude.

Keywords

- event-related

- potentials

- auditory perception

- reliability

- evoked potentials

Conclusion These findings show that amplitude responses are more robust for the speech stimulus when compared with its pure tone counterpart. The P300 indicated stability for latency and amplitude measures when the test-retest was applied. Reliability was higher for amplitude than for latency, with better agreement when the pure tone stimulus was used. However, further research with speech stimulus is needed to clarify how these stimuli are processed by the nervous system.
\end{abstract}

\section{Introduction}

Long latency auditory evoked potentials (LLAEP) have been used to monitor neurophysiological changes that compromise the cortical regions of the auditory pathway, in relation to skills such as cognitive processing, memory, attention, and auditory discrimination.

received

March 16, 2016

accepted

March 28, 2016

published online

April 26, 2016 10.1055/s-0036-1583527 ISSN $1809-9777$.
The P300 is considered an endogenous potential, since it reflects the individual's functional use of the stimulus and does not depend directly on their physical characteristics. ${ }^{1}$ It is related to cognitive skills, perception, and attention. The P3 component occurs when individuals consciously recognize a change in auditory stimulus. ${ }^{2,3}$

Copyright $\odot 2017$ by Thieme-Revinter

Publicações Ltda, Rio de Janeiro, Brazil
License terms

(요 (1) $\Theta \circledast$ 
The exact location of the origin of the P300 wave remains unknown. The possible neural generators of N200 and P300 waves result from the joint participation of several neural structures, that is, multiple generators. They involve areas of the supratemporal auditory cortex (N2), frontal cortex, and hippocampus (P300). ${ }^{3,4}$ LLAEPs evaluate the cortical activity involved in discrimination, integration, and attention skills. ${ }^{3,5}$

To elicit the P300, a wide variety of paradigms have been used, of which the "oddball" paradigm is the most utilized. In a process of active attention, different stimuli, with the same modality and different characteristics, ${ }^{6}$ are presented in a series such that one of them occurs relatively infrequently, that is, the oddball. ${ }^{7}$

The amplitude of the P300 wave is highly influenced by individual characteristics and latency over the time neural activity takes to travel along the auditory pathway, including time spent in synaptic transmission and neural conduction. ${ }^{8}$

Several authors ${ }^{9-17}$ have demonstrated that P300 latency and/or amplitude values in normal adults are replicable and stable, with no statistically significant test-retest differences at different time intervals. By contrast, other studies ${ }^{18,19}$ have exhibited test-retest variability in the P300 wave.

Studies have reported that a large number of factors can interfere in P300 results, although without reaching consensus. Primarily the attention component, ${ }^{3,4}$ stimulus intensity interferes directly in measures of wave amplitude and latency. ${ }^{20}$ Advancing age leads to variations in P300 values such as increased latency, ${ }^{21,22}$ decreased amplitude, ${ }^{23}$ and cognitive development. ${ }^{24}$ In children, the development changes observed in AEPs are related not only to anatomical and functional elements, but also to organizational patterns that occur with behavior and learning. ${ }^{24}$ Normal variation results from the association between age and cognitive maturity. ${ }^{3,24-26}$ There are also reports of sex and menstrual cycle interference. ${ }^{19,27}$

In light of the vast clinical applications of LLAEPs and the significant intra and interindividual variation, the test-retest stability of the P300 wave should be investigated.

\section{Objective}

The aim of the present study was to analyze test-retest (4-6 weeks apart) amplitude and latency variability of the P300 wave, using different auditory stimuli (pure tone and speech) in young adult women, without auditory processing disorders (APD).

\section{Methods}

The study was approved under protocol number 1376/11, and all participants gave their informed consent.

\section{Participants}

We selected the sample by convenience and was justified by the profile of students in the speech therapy course. Ten women, non-smoking, ranging in age between 17 and 30 years participated in the study.

As for some studies' conclusion that menstrual cycle and use of oral contraceptives do not affect the P300 wave or other
ERP components, ${ }^{28-30}$ we decided against controlling this variable.

Inclusion criteria were having a normal peripheral auditory system and auditory processing. Exclusion criteria were the presence of hearing loss, history of neurological and/or cognitive disorders, and the use of drugs acting on the central nervous system. Subjects received orientation for testing of AEPs as follows: avoid taking tea, coffee, and chocolate in the preceding 24 hours.

\section{Procedures}

The individuals underwent a basic audiological assessment consisting of tonal audiometry, vocal audiometry, and imitanciometry. Next, auditory processing behavior was assessed as a diagnostic criterion and only individuals with no auditory processing disorders were included in the present study.

LLAEP- P300 was recorded with a two-channel Smart EP USB Jr system (Intelligent Hearing System, Miami, USA), in a quiet setting. We placed electrodes on the vertex $(\mathrm{Cz})$ and on each side of the ear $\left(A_{1}\right.$ for the left ear and $A_{2}$ for the right ear), with the ground electrode $\left(\mathrm{F}_{\mathrm{pz}}\right)$ on the forehead, in accordance with the international $10-20$ system. ${ }^{31}$ We assessed the right and left ears separately, using ER-3A insert earphones. Skin was cleansed with gauze and abrasive paste. Surface electrodes were then placed over electrolytic paste (for optimizing electrical conductivity) and fixed with microporous adhesive tape. Accepted electrode impedance was up to five ohms, with a difference of up to two ohms between electrodes.

We used the following parameters to acquire P300: 300 monaural acoustic stimuli at frequencies of $1000 \mathrm{~Hz}$ for the frequent (85\%) and $2000 \mathrm{~Hz}$ for the rare (15\%), intensity of $75 \mathrm{~dB}$ SPL; recording window of 510 milliseconds; filter between 1 (high-pass) and $30 \mathrm{~Hz}$ (low-pass); speed presentation of 1.1 stimuli per second. Rare and frequent stimuli were randomly presented (oddball paradigm). ${ }^{7}$ Individuals remained seated and were instructed to pay attention and count out loud the number of occurrences of the rare stimulus, and to avoid artifact contamination caused by eye movement, subjects were asked to keep their eyes fixed on a target. $^{32}$ After we recorded $\mathrm{P} 300$ results with the pure tone, we elicited P300 by speech, using the same parameters. The /DA/ and /BA/ syllables were used for the rare and frequent acoustic stimulus, respectively.

We performed the analysis of $\mathrm{P} 300$ by waveform subtraction. The third waveform resulted from subtracting the frequent from the rare waveform, and we selected the wave with the highest positive peak after the N1-P2-N2 complex..$^{5,24}$ We marked the latency and amplitude of P300 on this curve. To obtain amplitude values of the P300 wave, the cursor was placed on the positive polarity wave (P300) as far as the negative polarity (N2). The latency reference values used were 225 to $365 \mathrm{msec}^{3}$, while those for amplitude ranged between 5 and 20 micro $V^{4}$

\section{Statistical Analysis}

Data obtained in descriptive analysis and presented in tabular form are expressed as mean, standard deviation, median, minimum, and maximum. 
Pearson's coefficient of variation, a measure of relative dispersion used to estimate the accuracy of experiments, represents the standard deviation expressed in percentage of the mean. Inferential analysis involved the following methods: Intra-subject agreement regarding measures of latency and amplitude was assessed by the intraclass correlation coefficient (ICC), ${ }^{33}$ and we analyzed the variation in these measures between stimuli (pure tone and speech) or between the left and right ears using the Wilcoxon signedrank test.

We evaluated the normal distribution of latency and amplitude measures by the Shapiro-Wilks test. We adopted a $5 \%$ significance level, and processed the statistical analysis using SAS 6.11 software (SAS Institute, Inc., Cary, North Carolina).

\section{Results}

We studied latency (msec) and amplitude $(\mu \mathrm{V})$ of the P300 wave in response to right and left ear stimulation for each variable (acoustic stimulus) and between sessions. We found no statistically significant differences between the right and left ears, in the electrophysiological assessment of AEP-P300. Thus, we grouped the ears $(n=20)$ for analyses.

Lower coefficient of variation values was found for latency, indicating that this is a more accurate measure, that is, with less response variability. The coefficient of variation of latency with speech stimulus was lower than that using pure tone $(-$ Table $\mathbf{1})$. The values obtained were similar at the two assessment sessions, with a lower mean for speech stimulus than pure tone. The variation in latency between pure tone and speech stimuli exhibited a descriptive level of $p=0.75$ at test and $p=0.17$ at retest, that is, no significant variation between assessments.

- Table 2 shows that measures of amplitude were similar between sessions, and that the mean values found for the pure tone stimulus were lower than those obtained for the speech stimulus. The coefficient of variation was more

Table 1 Measures of P300 latency with pure tone and speech stimuli, at test and retest

\begin{tabular}{|l|l|l|l|l|}
\hline \multirow{2}{*}{$\begin{array}{l}\text { Latency } \\
\text { (msec) }\end{array}$} & \multicolumn{3}{l|}{ Pure tone } & \multicolumn{2}{l|}{ Speech } \\
\cline { 2 - 5 } & Test & Retest & Test & Retest \\
\hline $\mathrm{n}$ & 20 & 20 & 20 & 20 \\
\hline Mean & 279.6 & 287.3 & 276.7 & 278.9 \\
\hline Median & 275.5 & 291.5 & 276.5 & 277.0 \\
\hline SD & 26.0 & 25.8 & 17.9 & 20.6 \\
\hline Minimum & 241 & 241 & 254 & 248 \\
\hline Maximum & 323 & 327 & 306 & 324 \\
\hline $\mathrm{CV}$ & $9.3 \%$ & $9.0 \%$ & $6.5 \%$ & $7.4 \%$ \\
\hline $\mathrm{Cl}$ & 11.39 & 11.29 & 7.85 & 9.04 \\
\hline
\end{tabular}

Abbreviations: Cl, confidence interval; CV, coefficient of variation; $\mathrm{n}$ of subjects, number of subject; SD, standard deviation.
Table 2 Measures of P300 amplitude with pure tone and speech stimuli, at test and retest

\begin{tabular}{|l|l|l|l|l|}
\hline \multirow{2}{*}{ Amplitude $(\mu \mathrm{V})$} & \multicolumn{2}{|l|}{ Pure tone } & \multicolumn{2}{l|}{ Speech } \\
\cline { 2 - 5 } & Test & Retest & Test & Retest \\
\hline $\mathrm{N}$ & 20 & 20 & 20 & 20 \\
\hline Mean & 9.8 & 9.3 & 13.8 & 13.4 \\
\hline Median & 9.7 & 7.2 & 14.1 & 13.8 \\
\hline $\mathrm{SD}$ & 4.8 & 5.6 & 4.1 & 4.4 \\
\hline Minimum & 3.6 & 3.0 & 7.7 & 5.9 \\
\hline Maximum & 18,9 & 25.8 & 23.4 & 23.8 \\
\hline $\mathrm{CV}$ & $48.9 \%$ & $60.0 \%$ & $29.6 \%$ & $32.6 \%$ \\
\hline $\mathrm{Cl}$ & 2.11 & 2.44 & 1.80 & 1.92 \\
\hline
\end{tabular}

Abbreviations: $\mathrm{Cl}$, confidence interval; $\mathrm{CV}$, coefficient of variation; $\mathrm{n}$ of subjects, number of subject; SD, standard deviation.

accurate using the speech than the pure tone stimulus. At the $5 \%$ level, there was a significant increase in amplitude using the speech stimulus compared with the pure tone, for $p=0.0003$ at test and $p=0.004$ at retest.

The intraclass correlation coefficient (ICC) was used to determine intrasubject agreement on the test-retest with measures of latency and amplitude using pure tone and speech stimuli. - Table 3 contains the intraclass correlation coefficient (ICC), its respective $95 \%$ confidence interval (CI) and p-value for the measures of latency and amplitude. A significance value of $1 \%$ was considered to obtain more robust interpretations.

There was statistical significance for intra-subject testretest, in measures of latency and amplitude. Agreement for latency was moderate, using both auditory stimuli. For amplitude, agreement was excellent for pure tone and good for speech.

- Figs. 1 and $\mathbf{2}$ illustrate the distribution of P300 amplitude and latency, for pure tone and speech stimuli between sessions.

\section{Discussion}

Normative data collected during the present study reflect that the P300 wave was significantly stable between sessions. The reliabilities found generally correspond well to those reported by others.

Ears were grouped $(n=20)$ since between the ears P300 latency and amplitude showed no statistically significant difference.

Mean latency of the P300 wave in the test-retest for the pure tone was $279.6 \mathrm{msec}$ and $287.3 \mathrm{msec}$, respectively, and for the speech stimulus $276.7 \mathrm{msec}$ and $278.9 \mathrm{msec}$. The mean values obtained were lower than in other studies with normal adults, all of which reported a mean of more than $300 \mathrm{msec}^{10,11,17,19,27,34}$ This disagreement may have occurred in the present study because auditory processing behavior was assessed, thereby reducing the interference of difficulties in the perceptual processing of auditory information in the nervous system. 
Table 3 Intra-subject agreement in measures of latency and amplitude with pure tone and speech stimuli

\begin{tabular}{|l|l|l|l|l|}
\hline & \multicolumn{2}{|l|}{ Pure tone } & \multicolumn{2}{l|}{ Speech } \\
\hline & Latency & Amplitude & Latency & Amplitude \\
\hline Delta & $7.8 \pm 5.2$ & $-0.54 \pm 0.66$ & $2.20 \pm 4.08$ & $-0.42 \pm 0.90$ \\
\hline ICC & 0.58 & 0.84 & 0.57 & 0.60 \\
\hline Cl 95\% & $0.20-0.81$ & $0.65-0.93$ & $0.19-0.80$ & $0.18-0.80$ \\
\hline$p$ & 0.003 & $<0.001$ & 0.003 & 0.003 \\
\hline
\end{tabular}

Abbreviations: CI 95\%, confidence interval of 95\% for ICC; Delta, was expressed by the mean \pm standard error; ICC, intraclass correlation coefficient.

The variation in latency was between $241 \mathrm{msec}$ and $327 \mathrm{msec}$ with the pure tone and $248 \mathrm{msec}$ and $324 \mathrm{msec}$ with speech. The values obtained are within the range proposed in the literature ${ }^{3}$ for adolescents and adults (17 to 30 years). There was a slight increase in the general latency mean in the retest for both stimuli, which also occurred in another study that analyzed test-retest using the pure tone stimulus. ${ }^{19}$ The results suggest that there was no learning effect in the second assessment, the task did not become easier, and non-auditory factors such as attention and lack of motivation may have influenced the response. These data disagree with several findings that showed a slight decline in latency in the second assessment. ${ }^{10,12,14,17}$ The authors put forward several factors to explain the changes observed, such as the learning effect or a decrease in task difficulty due to previous experience, reduced anxiety, and greater fatigue control. $^{10,12}$

Pure tone amplitude exhibited mean values of $9.8 \mu \mathrm{V}$ and $9.3 \mu \mathrm{V}$ in the test-retest, respectively, with a minimum value of $3.0 \mu \mathrm{V}$ and maximum of $25.8 \mu \mathrm{V}$. For the speech stimulus the means were $13.8 \mu \mathrm{V}$ (test) and $13.4 \mu \mathrm{V}$ (retest), with a minimum of $5.9 \mu \mathrm{V}$ and maximum of $23.8 \mu \mathrm{V}$. The minimum and maximum amplitude values obtained in the sample are outside the ranges between 10 and $20 \mu V^{2}$ and between 5 and $20 \mu V^{4}$ suggested in the literature. However, they agree with another study ${ }^{27}$ that used a pure tone stimulus to assess adult women, where amplitude ranges were between $3.24 \mu \mathrm{V}$ and $24.9 \mu \mathrm{V}$. This greater variability in responses may be due to interference from the menstrual cycle, which was not controlled in the present study and, according to the authors, can influence amplitude values. ${ }^{19,27}$

The auditory stimuli used exhibited a statistically significant difference in response values, with higher speech amplitudes. Test-retest analysis showed no statistical difference between-session, indicating that the wave exhibited no habituation process. ${ }^{14}$ The physiology of the P300 wave is controversial, but there are literature reports that P300 amplitude is correlated with the number of neural sources that the attention system needs to perform the task, and can be used to infer the difficulty in detecting and discriminating the stimulus. ${ }^{35,36}$ In relation to task difficulty, it is suggested that amplitudes be higher for easier discrimination tasks, and lower for more difficult tasks. Likewise, latency declines when the discrimination task is easier and rises for more difficult tasks. $^{35}$

The data show that the speech stimulus generates a more robust response than a pure tone. Following the assumption of task complexity, this study exhibited greater facility with speech stimulus, showing lower latencies and higher amplitudes for the P300 wave. Our findings corroborate those of authors $^{37}$ that compared nonverbal and verbal stimuli. They used one word (mommy) as rare stimulus and a $1000 \mathrm{~Hz}$ tone as frequent stimulus. There was no statistically significant difference for P300 latency and P300 amplitudes were higher

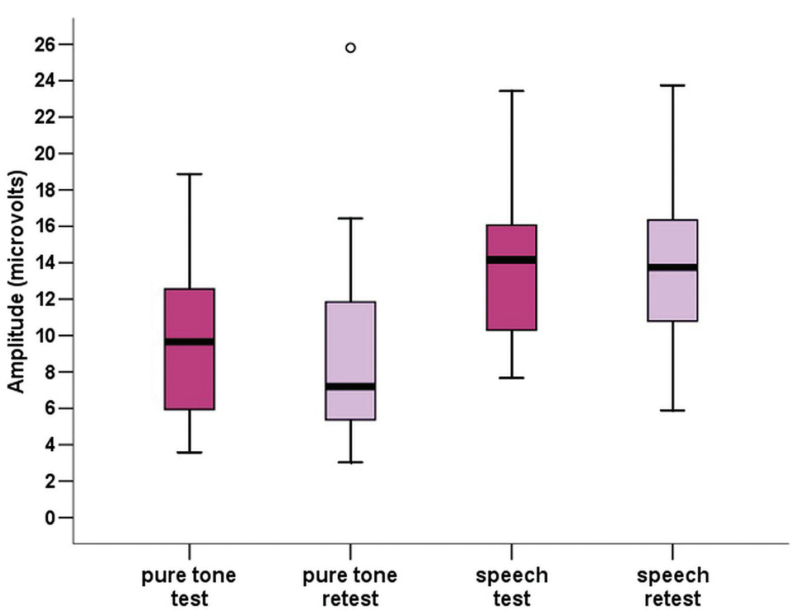

Fig. 1 Box Plot Amplitudes.

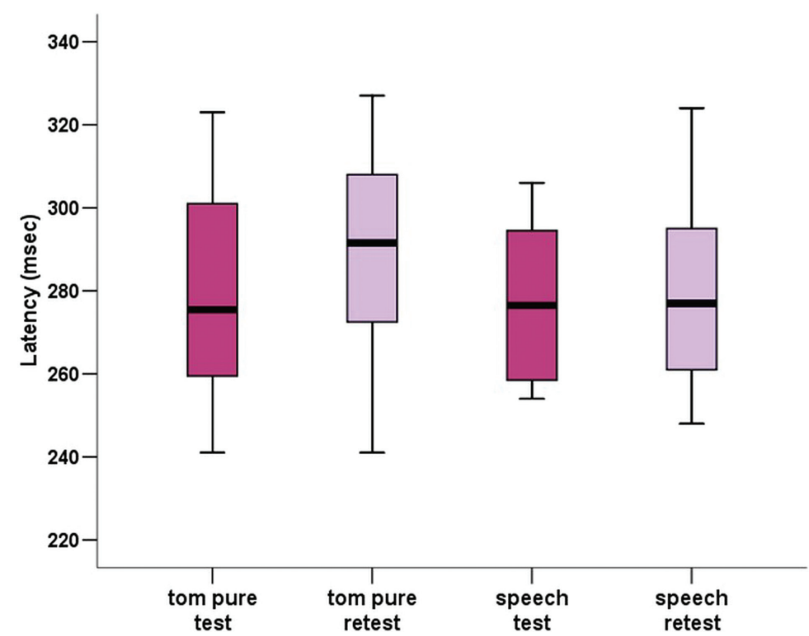

Fig. 2 Box Plot Latencies. 
with verbal stimulus, with a statistically significant difference. These results differ from those of another study ${ }^{38}$ showing a statistically significant difference with higher latency and lower P300 amplitude, when the verbal stimulus is used.

The use of speech stimulus showed a lower SD for both test sessions, as well as lower coefficient of variation values when compared with pure tones. These data suggest that the speech stimulus exhibits lower response variability for the P300 wave. Since most studies performed with LLAEP prioritized the use of nonverbal (pure tones) stimulus to capture the P300 wave, it is important that further studies be conducted to compare how these stimuli are processed by the nervous system, thereby contributing to understanding the different changes that can involve the auditory system.

The AEP-P300 indicated stable latency and amplitude measures on the test-retest, with statistically significant agreement. Reliability of P300 amplitude was higher than latency in the present study, as well as in earlier investigations. ${ }^{10,11,14,15,17}$ P300 reliability was assessed in other studies and considered satisfactory at different time intervals, such as intrasession, ${ }^{13-15}$ days, ${ }^{10,14,15}$ months, ${ }^{14}$ and years. $^{13,16,17}$ The results indicate that P300 amplitude, calculated based on the difference between waves, is a stable marker for assessment between sessions, with better reproducibility for the pure tone stimulus. The greater reliability and methodological advantages of amplitude in relation to latency should encourage future efforts to clarify its functional significance.

Several studies ${ }^{11,13-15,17}$ have investigated P300 reliability, using the auditory oddball paradigm, with recordings at the $\mathrm{Cz}$ site, and reported intersession reliability (Pearson's correlation coefficient) for P300 latency ranging from 0.48 to 0.73 , and amplitude between 0.51 and $0.62 .^{13-15,17}$ Studies that conduct a retest at the same session, with recordings at $\mathrm{Cz}$, obtained values ranging between 0.43 and 0.93 for latency ${ }^{10,11,13-15,17}$ and 0.50 and 0.89 for amplitude. ${ }^{11,13-15,17}$ For young adults, studies have shown satisfactory correlation for the retest at the same session or with intervals. However, correlations were slightly higher when they were retested at the same session than with intervals of years. It is believed that when participants return to a new session after a period of time, they may be in another state, that is, more or less tired, alert, healthy, among others, which suggests lower correlation with higher time intervals. ${ }^{17}$

The correlation coefficients for latency using both auditory stimuli in the present study are within the range reported in the literature, ${ }^{15}$ indicating moderate agreement. For analysis of amplitude, agreement was excellent for pure tones and good for speech. This study obtained high response reproducibility, confirming that the P300 wave is a reliable measure, with significant stability in repetition measures, as well as for observing differences caused by physiological changes. ${ }^{10}$ These findings are in agreement with the literature, which indicates good reliability in P300 measures, in normal young adults, when test-retest is conducted, and favor its application for the study of normal and altered cognitive processes.

\section{Conclusion}

In conclusion, the present study provided data indicating more robust amplitude responses for the speech stimulus when compared with pure tones, with a statistically significant difference. The LLAEP-P300 exhibited stability in latency and amplitude measures when the test-retest is applied, and statistically significant agreement. Amplitude reliability was higher than that of latency, with excellent agreement when the pure tone stimulus was used.

\section{References}

1 Sutton S, Braren M, Zubin J, John ER. Evoked-potential correlates of stimulus uncertainty. Science 1965;150(3700):1187-1188

2 Musiek FE, Baran JA, Pinheiro ML. Neuro-Audiology: Case Studies. San Diego: Singular Publishing Company; 1994:20-21

3 McPherson DL. Late potentials of the auditory system. San Diego: Singular Publishing Group, Inc.; 1996

4 Hall JW. Handbook of auditory evoked responses. 3nd ed. Massachusetts (Boston): Allyn and Bacon; 1990

5 Kraus N, McGee T. Potenciais auditivos de longa latência. In: Katz J. Tratado de audiologia clínica. São Paulo: Manole; 1999:403-20

6 Duarte JL, Alvarenga KdeF, Banhara MR, Melo AD, Sás RM, Costa Filho OA. P300-long-latency auditory evoked potential in normal hearing subjects: simultaneous recording value in $\mathrm{Fz}$ and $\mathrm{Cz}$. Braz J Otorhinolaryngol 2009;75(2):231-236

7 Squires NK, Squires KC, Hillyard SA. Two varieties of long-latency positive waves evoked by unpredictable auditory stimuli in man. Electroencephalogr Clin Neurophysiol 1975;38(4):387-401

8 Eggermont JJ. Electric and magnetic fields of synchronous neural activity. In: Burkard RF, Don M, Eggermont JJ (Eds.). Auditory evoked potentials. Baltimore: Lippincott William \& Wilkins; 2006:2-21

9 Polich J, Howard L, Starr A. P300 latency correlates with digit span. Psychophysiology 1983;20(6):665-669

10 Sklare DA, Lynn GE. Latency of the P3 event-related potential: normative aspects and within-subject variability. Electroencephalogr Clin Neurophysiol 1984;59(5):420-424

11 Polich J. Normal variation of P300 from auditory stimuli. Electroencephalogr Clin Neurophysiol 1986;65(3):236-240

12 Kileny PR, Kripal JP. Test-retest variability of auditory eventrelated potentials. Ear Hear 1987;8(2):110-114

13 Segalowitz SJ, Barnes KL. The reliability of ERP components in the auditory oddball paradigm. Psychophysiology 1993;30(5): 451-459

14 Kinoshita S, Maeda H, Nakamura J, Kodama E, Morita K. Reliability of the probability effect on event-related potentials during repeated testing. Kurume Med J 1995;42(4):199-210

15 Kinoshita S, Inoue M, Maeda H, Nakamura J, Morita K. Long-term patterns of change in ERPs across repeated measurements. Physiol Behav 1996;60(4):1087-1092

16 Sandman CA, Patterson JV. The auditory event-related potential is a stable and reliable measure in elderly subjects over a 3 year period. Clin Neurophysiol 2000;111(8):1427-1437

17 Walhovd KB, Fjell AM. One-year test-retest reliability of auditory ERPs in young and old adults. Int J Psychophysiol 2002;46(1): 29-40

18 Matas CG, Hataiama NM, Gonçalves IC. Estabilidade dos potenciais evocados auditivos em indivíduos adultos com audição normal. Rev Soc Bras Fonoaudiol. 2011;16:37-41

19 Reis ACMB, Frizzo ACF, Lozano AC, Santos FR, Anastasio ART, Hyppolito MA. Variability of registration latency and amplitude of the auditory evoked potential long latency (P3) in the condition test and retest. Audiol. Communic Res 2014;19(3):293-298 
20 Covington JW, Polich J. P300, stimulus intensity, and modality. Electroencephalogr Clin Neurophysiol 1996;100(6):579-584

21 Goodin DS, Squires KC, Henderson BH, Starr A. Age-related variations in evoked potentials to auditory stimuli in normal human subjects. Electroencephalogr Clin Neurophysiol 1978;44(4):447-458

22 Polich J. P300 in clinical applications: meaning, method, and measurement. Am J EEG Technol 1991;31(3):201-231

23 Verleger R, Neukäter W, Kömpf D, Vieregge P. On the reasons for the delay of P3 latency in healthy elderly subjects. Electroencephalogr Clin Neurophysiol 1991;79(6):488-502

24 Polich J, Ladish C, Burns T. Normal variation of P300 in children: age, memory span, and head size. Int J Psychophysiol 1990;9(3):237-248

25 Squires K, Goodin D, Starr A. Event-related potentials in development, aging and dementia. In: Lehman D, Callaway E, eds. Human evoked potentials. New York: Plenum Publishing Co; 1979

26 Musiek FE. Probing brain function with acoustic stimuli. ASHA 1989;31(8):100-106, 55

27 Machado CSS, Carvalho ACO, Silva PLG. Standard characterization of P300 in young adults. Rev Soc Bras Fonoaudiol. 2009;14(1):83-90

28 Fleck KM, Polich J. P300 and the menstrual cycle. Electroencephalogr Clin Neurophysiol 1988;71(2):157-160

29 Fagan PL, Church GT. Effect of the menstrual cycle on the auditory brainstem response. Audiology 1986;25(6):321-328

30 Howard R, Mason P, Taghavi E, Spears G. Brainstem auditory evoked responses (BAERs) during the menstrual cycle in women with and without premenstrual syndrome. Biol Psychiatry 1992; 32(8):682-690

31 Jasper HH. Report of the committee on methods of clinical examination in electroencephalography. Eletroenceph Clin Neurophysiol. 1958;10:370-375

32 Vaughan HG Jr, Ritter W. The sources of auditory evoked responses recorded from the human scalp. Electroencephalogr Clin Neurophysiol 1970;28(4):360-367

33 Bartko JJ, Carpenter WT Jr. On the methods and theory of reliability. J Nerv Ment Dis 1976;163(5):307-317

34 Schochat E, Matas CG, Samelli AG, Mamede Carvallo RM. From otoacoustic emission to late auditory potentials P300: the inhibitory effect. Acta Neurobiol Exp (Warsz) 2012;72(3):296-308

35 Polich J. Task difficulty, probability, and inter-stimulus interval as determinants of P300 from auditory stimuli. Electroencephalogr Clin Neurophysiol 1987;68(4):311-320

36 Kok A. On the utility of P3 amplitude as a measure of processing capacity. Psychophysiology 2001;38(3):557-577

37 Lew HL, Slimp J, Price R, Massagli TL, Robinson LR. Comparison of speech-evoked $\mathrm{v}$ tone-evoked P300 response: implications for predicting outcomes in patients with traumatic brain injury. Am J Phys Med Rehabil 1999;78(4):367-371

38 Massa CG, Rabelo CM, Matas CG, Schochat E, Samelli AG. P300 with verbal and nonverbal stimuli in normal hearing adults. Braz J Otorhinolaryngol 2011;77(6):686-690 